\title{
In vitro assessment of some deodorant ingredients and determination of malodor inhibiting potentials of ascorbic acid, orlistat and mastic gum Rasha Mosbah ${ }^{1}$, Fathy Serry ${ }^{2}$, Eman El Masry² \\ ${ }^{1}$ Zagazig University Hospitals \\ ${ }^{2}$ Department of Microbiology and Immunology, Faculty of Pharmacy, Zagazig University, Zagazig, Egypt
}

\begin{abstract}
Axillary microbial flora has a role in sweat odor formation by transformation of odorless natural secretions into volatile odorous molecules. From 190 axillary isolates obtained from healthy volunteers, 97 isolates, representing three genera; Stahylococcus (39), Micrococcus (13), Corynebacterium (45) were screened for their ability to produce malodorous metabolites from testosterone oenanthate ester andhydroxyprogesterone caproate by sensory, and chromatographic assessments. Only lipophilic Corynebacterium $\operatorname{spp}(C$. jeikeium and C. macginleyi) and Staphylococcus capitisisolates were able to metabolize testosterone and hydroxy progesterone esters, with malodorous metabolites from the former only.Quantification of the yield of conversion of substrates into metabolites by the action of C. jeikeium was carried out using gas chromatography/mass spectrometryGC/MS. The odourous metabolites are suspected to be Androstadienone and 5- $\alpha$-dihydrotestosterone, based on mass spectra and previously reported data. The effect of some selected material as potential deodorants on such metabolic activities was studied. In the absence of inhibitor, $99.6 \%$ of testosterone ester substrate was converted into metabolites. Ascorbic acid and orlistat dramatically inhibited testosterone ester metabolism allowing only $6.9 \%$, and 0.6 $\%$ conversion, respectively. While mastic gum allowed $84.3 \%$ conversion, no malodor was observed. These three components have the potentials to be used as deodorants.
\end{abstract}

\section{INTRODUCTION}

Overproduction of sweat, sweaty skin and body odors are unpleasant for many social groups. Deodorants are designed to combat malodor generated from bacterially modified sweat. Sweat is normally a clear odorless liquid containing odorless C3-fatty acid [(iso) butyric acid, isovaleric acid and propionic acid] triglycerides, which liberate odorous free fatty acid upon hydrolysis by bacterial esterases (Holzle, 2002; Pierard et al., 2003). Androgenic steroids such as 16 androstenes, $5 \alpha$-androstenol and $5 \alpha$ androstenone secreted as odorless soluble salts are liberated by hydrolytic ßlyaseexoenzymes of bacteria as odorous volatile steroids (Gower et al., 1997 a; Starkenmann et al., 2013; Zeng et al., 1991; Zeng et al., 1992). Although the antimicrobials commonly employed as axillary deodorants have excellent safety profiles (Bhargava and Leonard, 1996), it has been argued that disruption or modification of this normal skin flora may predispose to opportunistic infections (Leyden et al., 1987). Furthermore, concerns aboutthe spread of resistant subpopulations of bacteria and about the release of antimicrobials into the environment have effectively precluded the widespread use of these agents in some European countries. For these reasons there have been very real demands for effective non-antimicrobial routes to underarm deodorancy. A number of approaches have been attempted to interfere with the bio-transformational steps leading to the production of odorous compounds.

The present study aims to screen for and evaluate the malodor inhibiting ability of some ingredients of deodorant formulation and some chemicals or natural products for their potential deodorant activities. 


\section{MATERIALS and METHODS}

\section{Specimens collection}

Axillary swabs obtained by rubbing sterile cotton swab against the axilla were collected from adult healthy volunteers, who were receiving no medication or using any form of deodorants or antiperspirants prior to specimen collection with at least forty eight hours (American Society for Testing and Materials; ASTM 1988). The swabs were immediately cultured on selective and nonselective media (Haustienet al., 1993) and the isolates were identified according to Koneman et al. (1997a).

\section{Screening for malodor producing isolates}

Fifteen milliliters Trypticase soy broth medium (Oxoid, Basingstoke, Hampshire-England) containing $\quad 0.1 \%$ Tween 80 and $5 \mathrm{mg} / \mathrm{ml}$ of steroid substrate (testosterone oenanthate, or hydroxy progesterone caproate)in 100-ml flask was inoculated with $100 \mu \mathrm{l}$ of bacterial inoculum of approximately $10^{8} \mathrm{CFU} / \mathrm{ml}$ froman overnight culture in Trypticase soy broth. Controls without substrate, uninoculated reaction mixture, and culture media were run in parallel with the test. All flasks were incubated with shaking at $220-250 \mathrm{rpm} / \mathrm{min}$ at $37^{\circ} \mathrm{C}$ in a shaking water bath for 72 hours (Austin and Ellis, 2003). Cultures were inspected for malodor production by sensory assessment and subjected to thin layer chromatography (TLC) and gas chromatography-mass spectrometry (GC/MS) analysis.

\section{Screening for malodor producing isolates by sensory assessment}

Assessment of malodor production from testosterone oenanthate as a steroidal substrate was based on the in vitro odor production model describedby Froebe et al., (1990) and Rennie et al., (1990) by smelling the odor of the blinded cultures and controls by a panel of two or three judges and each was given a description according to the presence and intensity of malodor produced.

\section{Thin Layer Chromatography (TLC)}

Test isolates' cultures containing steroid substrateas well as controls were extracted each with $2 \times 5 \mathrm{ml}$ ethyl acetate and the pooled extracts were evaporate and the residues were dissolved in $1 \mathrm{ml}$ methanol. Five microliters of methanolic extracts were spotted onto silica gel plates that were developed using chloroformmethanol $(95: 5 \mathrm{v} / \mathrm{v})$ solvent systems (Edwards et al., 2003). The developed plates were examined under UV lamp (254 nm) (Petrino et al., 1993), or after exposure to iodine vapours (Lupo $\mathrm{Di}$ Priscoet al., 1968) to visualize the spots and retention values (Rf) were calculated for resolved spots.. Rf, is defined as the distance traveled by the compound divided by the distancetraveled by the solvent from the base line

\section{distance traveled by the compound $\mathrm{R}_{\mathrm{f}}-\frac{\text { distance traveled by the solvent fiont }}{\text { ding }}$}

Different solvent systems were used. Spots of the metabolites were interpreted comparing with references and controls.

Gas chromatography -mass
spectrometric (gc/ms) analysis of
metabolites

Ethyl acetate extracts of cultures and appropriate controls were evaporated in a rotary evaporator and the residues were dissolved in methyl alcohol. The crude extracts were first derivatized into tbutyldimethylsilyl ethers (TBDMS) to protect hydroxyl group and opentafluorbenzyloxime (PFB) to protect ketonic group (Gower et al., 1997b; Austin and Ellis, 2003).The derivatized extracts were subjected to gas chromatographymass spectrometry using a Shimadzu instrument (GC/MS QP5050A) fitted on DB-1 column (J\&W Scientific) with a length of $30 \mathrm{~m}$, inner diameter of $0.53 \mathrm{~mm}$, and film thickness of $1.5 \mu \mathrm{m}$. The temperature program was initially set to $80^{\circ} \mathrm{C}$ for $2 \mathrm{~min}\left(10^{\circ} \mathrm{C} / \mathrm{min}\right)$, then subsequently increased to $200^{\circ} \mathrm{C}$ $\left(20^{\circ} \mathrm{C} / \mathrm{min}\right)$ and finally held at $300^{\circ} \mathrm{C}$ for 1 min (injector temperature, $280^{\circ} \mathrm{C}$; 
detectortemperature, $300^{\circ} \mathrm{C}$ ). Carrier gas was helium, ionization mode was at $70-\mathrm{eV}$, detector voltage was $2.74 \mathrm{kV}$, and the mass range was $40-550 \mathrm{~m} / \mathrm{z}$. Steroid metabolites were identified by prediction from molecular ion and fragmentation patterns.

\section{Screening for potential inhibitors of malodor production}

Some substances were tested for their malodour inhibiting potential. The same procedure for screening for malodour production mentioned above was used with the exception that the test substance was added, at sub-inhibitory concentration; were surface inoculated with $5 \mu \mathrm{l}$ of the test isolates. A 0.5 McFarland standardized suspension of the test organism (equivalent to $1.5 \times 10^{8}$ cells $/ \mathrm{ml}$ ) prepared from a concentration that's equal or less than 1/4 MIC which was taken, as the lowest concentration of antimicrobial agents at which there was no visible growth of the organism.

\section{Determination of bacterial inhibitory effect of deodorants}

The minimum inhibitory concentrations (MICs) of the potential antimicrobial deodorant against test isolates were determined by agar dilution method according to NCCLS (2002). Two-fold serial dilutions of the tested compounds were prepared in MuellerHinton agar medium (Oxoid). The plates overnight culture in brain heart infusion broth was further diluted so as to contain approximately $10^{5} \mathrm{CFU}$ per spot. The plates were incubated at $37^{\circ} \mathrm{C}$ for $18 \mathrm{~h}$.

Table 1. Screening for malodor producing isolates from testosterone oenanthate by sensory assessment and TLC.

\begin{tabular}{lclc}
\multicolumn{1}{c}{ Species } & $\begin{array}{c}\text { No. of } \\
\text { isolates }\end{array}$ & \multicolumn{1}{c}{ Odor description } & Rfvalues for resolved spots \\
\hline C. jeikeium & 16 & Urinous bad odor & $0.4,0.5,0.6,0.7,0.9$ \\
C. macginleyi & 4 & Urinous bad odor & $0.4,0.5,0.6,0.7,0.9$ \\
C. callionae & 3 & Distinctive bad odor & $0.7,0.9$ \\
C. cystitidis & 3 & Distinctive bad odor & $0.7,0.9$ \\
C. afermentans & 2 & Distinctive bad odor & $0.7,0.9$ \\
C. amycolatum & 3 & Distinctive bad odor & $0.7,0.9$ \\
C. minutissimum & 4 & Distinctive bad odor & $0.7,0.9$ \\
C. pilosum & 3 & Distinctive bad odor & $0.7,0.9$ \\
C. striatum & 3 & Distinctive bad odor & $0.7,0.9$ \\
C. xerosis & 4 & Distinctive bad odor & $0.7,0.9$ \\
S. aureus & 10 & Moderate odor & $0.7,0.9$ \\
S. epidermidis & 13 & Moderate odor & $0.7,0.9$ \\
S. hominis & 4 & Moderate odor & $0.7,0.9$ \\
S. cohnii & 4 & Moderate odor & $0.7,0.9$ \\
S. capitis & 3 & Urinous bad odor & $0.7,0.9$ \\
S. saprophyticus & 5 & Moderate odor & $0.7,0.9$ \\
M. luteus & 6 & Rancid bad odor & $0.7,0.9$ \\
M. lylae & 4 & Rancid bad odor & $0.7,0.9$ \\
D. nishinomiyaensis & 3 & Rancid bad odor & $0.7,0.9$ \\
\hline
\end{tabular}

\section{RESULTS}

One hundred and ninety isolates recovered from volunteers were identified to species level representing 111 Staphylococcus spp., 34 Micrococcus spp. and 45 Corynebacterium spp. All Cornyebacterium isolates and representative isolates of Staphylococcus (39) and Micrococcus (13) were tested for their ability to produce malodor from cultures containing testosterone ester as substrate. 
Screening for malodor producing isolates from testosterone oenanthate

All tested Micrococcus isolates produced a bad rancid odor but not a sweaty ruinous odor. None of the tested staphylococcal isolates could produce distinctive malodor except $S$. capitis isolates (3) which produced a strong urinous malodor. All lipophilic corynebacteria (16 C. jiekieum and $4 C$. macginleyi) produced offensive sweaty urinousodor, while non-lipophilic Corynebacterium species produced less intensive malodor. Control cultures produced no malodor.

TLC analysis for cultures of isolates demonstrating bad odor from testosterone revealed three extra spots,possibly representing the metabolites with $\mathrm{Rf}$ values $0.6,0.5$ and 0.4 ; in addition to two spots representing the substratecontrol with $\mathrm{Rf}$ values 0.9 and 0.7.Cultures of isolates that did not produce malodor from testosterone, showed no extra spots in addition to that of the substrate. Controlsof culture media and inoculated cultures without substrate showed no distinctive spots (Table 1). GCMS analysis of extracts from culture producing malodor (Figures 1 \& 2 ) showed two major bacterial metabolites of testosterone oenanthate (peaks $1 \& 2$ ).

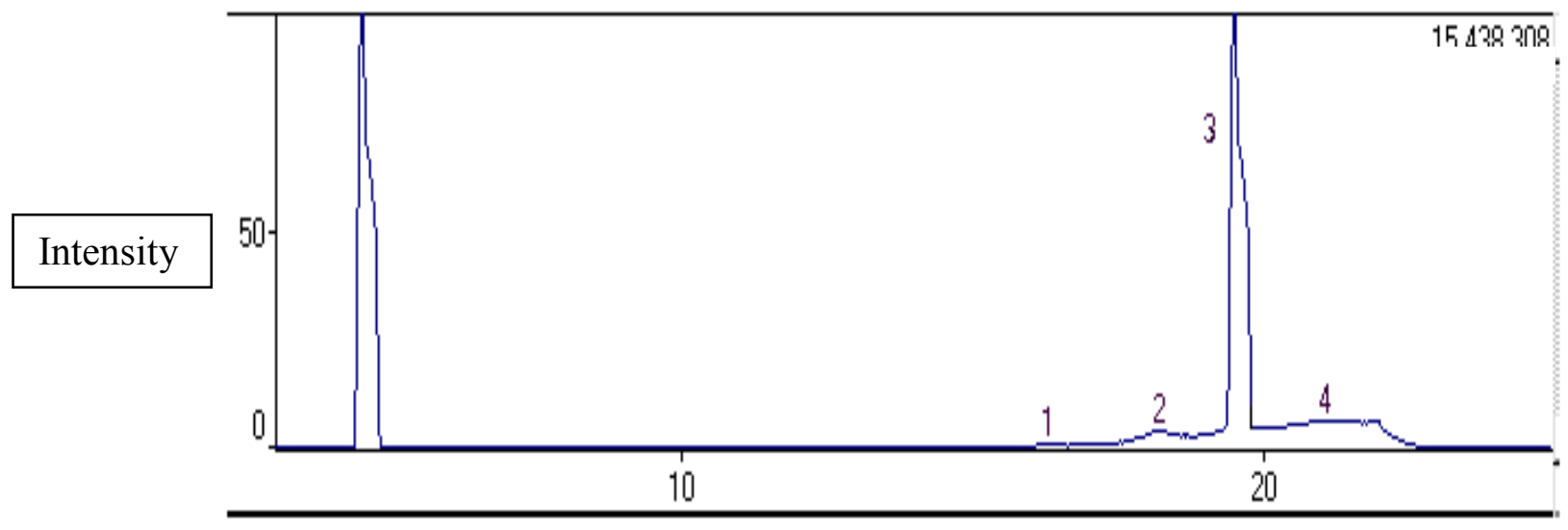

Figure 1. GC/MS analysis of extract of control containing culture media and testosterone oenanthate showing the substrate at peak 3 .

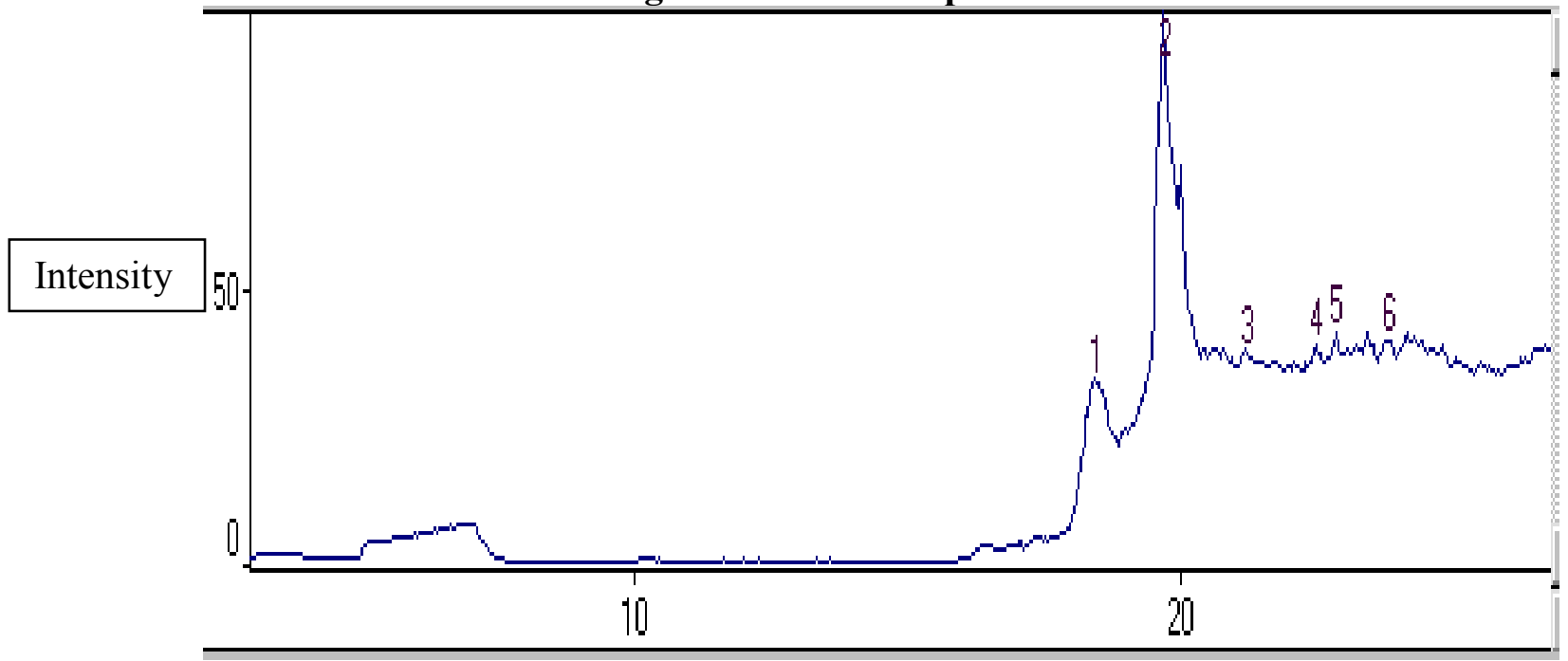

Figure 2. GC/MS analysis of extract of Corynebacterium jeikeium culture containing testosterone oenanthate after $\mathbf{7 2}$ hours incubation, showing two major metabolites of the testosterone oenanthate at peak $1 \& 2$. 


\section{Screening for malodor producing isolates from hydroxy progesterone caproate}

Ethyl acetate extracts of inoculated reaction mixture and controls were subjected to TLC. The mobile phase used was chloroform: ethanol $(9: 1 \mathrm{v} / \mathrm{v})$. It was found that only testosterone metabolizing isolates could metabolize hydroxy progesterone caproate and produce nonodorous metabolites. Lipophilic Corynebacteria and Staphylococcus capitis isolates were found to be able to produce two major non-odorous metabolites (I \& II) from hydroxy progesterone caproate as the substrate with Rf values 0.9 and 0.5 in (chloroform :methanol). Metabolite I is more polar than the substrate with $\mathrm{Rf}$ value 0.43 and metabolite II which is less polar than the substrate with $\mathrm{Rf}$ value 0.58 (Table 2). Controls containing substrate showed the Rf values of 0.9 and 0.5. Controls containing microbiological media showed no spots.

Table 2. Screening for malodor producing isolates from hydroxyprogesterone caproate by sensory assessmentand TLC chloroform:methanol (95:5 v/v)

\begin{tabular}{lccc}
\hline Species & $\begin{array}{c}\text { No. of } \\
\text { isolates }\end{array}$ & Odor description & $\begin{array}{c}\text { Rf values for } \\
\text { resolved spots }\end{array}$ \\
\hline C. jeikeium & 16 & Faint bacterial culture odor & $0.43,0.5,0.58,0.9$ \\
C. macginleyi & 4 & Faint bacterial culture odor & $0.43,0.5,0.58,0.9$ \\
C. callionae & 3 & Faint bacterial culture odor & $0.5,0.9$ \\
C. cystitidis & 3 & Faint bacterial culture odor & $0.5,0.9$ \\
C. afermentans & 2 & Faint bacterial culture odor & $0.5,0.9$ \\
C. amycolatum & 3 & Faint bacterial culture odor & $0.5,0.9$ \\
C. minutissimum & 4 & Faint bacterial culture odor & $0.5,0.9$ \\
C. pilosum & 3 & Faint bacterial culture odor & $0.5,0.9$ \\
C. striatum & 3 & Faint bacterial culture odor & $0.5,0.9$ \\
C. xerosis & 4 & Faint bacterial culture odor & $0.5,0.9$ \\
S. aureus & 10 & Faint bacterial culture odor & $0.5,0.9$ \\
S. epidermidis & 13 & Faint bacterial culture odor & $0.5,0.9$ \\
S. hominis & 4 & Faint bacterial culture odor & $0.5,0.9$ \\
S. cohnii & 4 & Faint bacterial culture odor & $0.5,0.9$ \\
S. capitis & 3 & Faint bacterial culture odor & $0.43,0.5,0.58,0.9$ \\
S. saprophyticus & 5 & Faint bacterial culture odor & $0.5,0.9$ \\
M. luteus & 6 & Rancid bad odor & $0.5,0.9$ \\
M.lylae & 4 & Rancid bad odor & $0.5,0.9$ \\
D. nishinomiyaensis & 3 & Rancid bad odor & $0.5,0.9$ \\
\hline & & & \\
\hline & & &
\end{tabular}

Screening for potential inhibitors of malodor production by sensory assessment and TLC

Test substances, at sub-inhibitory concentrations $(\leq 1 / 4 \mathrm{MIC})$, were screened for inhibition of malodor production in Corynebacterium jeikeium cultures containing testosterone oenanthate after 72 hours incubation by sensory assessment.Extracts of cultures in presence and absence of inhibitors were analysed by TLC (Table 3 and Figure 6). Bergamot oil, vanillin and peppermint extract, masked the formed odor but did not inhibit metabolite formation. Ascorbic acid, retinyl palmitate, $\alpha$-tocopherol acetate and selenium dioxide inhibited the formation of malodorous metabolites. Also, triethyl citrate, mastic gum, cupric sulfate, zinc sulfate, EDTA and orlistat inhibited malodor formation. Triclosan, ethylene glycol, polyethylene glycol, musk xylol and alum did not inhibit the formation of malodorous metabolites (Table 3). Extracts of the reaction mixture that demonstrated additional spots over the reaction mixture containing inhibitorwere subjected to further investigation. 
Table 3.Evaluation of malodor inhibiting potential of tested material by sensory assessment and TLC

\begin{tabular}{|c|c|c|c|c|}
\hline \multirow[t]{2}{*}{ Material tested } & \multirow{2}{*}{$\begin{array}{l}\text { Conc } \\
(\% \mathrm{w} / \mathrm{v})\end{array}$} & \multirow{2}{*}{$\begin{array}{c}\text { Odor } \\
\text { description } * *\end{array}$} & \multicolumn{2}{|r|}{ TLC } \\
\hline & & & Spots number & $\mathrm{Rf}$ \\
\hline $\mathrm{ZnSO}_{4}$ & 0.2 & $\bar{F}$ & 2 & $0.9,0.5$ \\
\hline $\mathrm{CuSO}_{4}$ & 0.1 & $\mathrm{~F}$ & 2 & $0.9,0.5$ \\
\hline Triethyl citrate & 2 & $\mathrm{~F}$ & 2 & $0.9,0.5$ \\
\hline Orlystat & $(0.04)$ & $\mathrm{F}$ & 2 & $0.9,0.5$ \\
\hline$\alpha$-tocopherol acetate & 2 & $\mathrm{~F}$ & 3 & $0.9,0.5,0.6^{*}$ \\
\hline Retinylpalmitate & $2000 \mathrm{IU}$ & $\mathrm{F}$ & 3 & $0.9,0.5,0.95^{*}$ \\
\hline Selenium dioxide & 0.0025 & $\mathrm{~F}$ & 2 & $0.9,0.5$ \\
\hline Ascorbic acid & $\begin{array}{c}0.05 \\
(0.006)\end{array}$ & $\mathrm{F}$ & 2 & $0.9,0.5$ \\
\hline Vanillin & 0.0025 & M & 6 & $0.9,0.5,0.45,0.4,0.35,0.2 *$ \\
\hline Mastic gum & $\begin{array}{c}0.025 \\
(0.006)\end{array}$ & M & 3 & $0.9,0.5,0.45$ \\
\hline EDTA & 0.025 & M & 2 & $0.9,0.5$ \\
\hline Bergamot oil & 0.1 & MB & 5 & $0.9,0.5,0.45,0.4,0.35$ \\
\hline Peppermint oil & 0.016 & MB & 5 & $0.9,0.5,0.45,0.4,0.35$ \\
\hline Alum & 0.1 & USB & 5 & $0.9,0.5,0.45,0.4,0.35$ \\
\hline Ethylene glycol & 0.2 & USB & 5 & $0.9,0.5,0.45,0.4,0.35$ \\
\hline Triclosan & 0.00005 & USB & 5 & $0.9,0.5,0.45,0.4,0.35$ \\
\hline Polyethylene glycol & 1 & USB & 5 & $0.9,0.5,0.45,0.4,0.35$ \\
\hline Musk Xylol & 1 & USB & 5 & $0.9,0.5,0.45,0.4,0.35$ \\
\hline
\end{tabular}

Table 4. GC/MS data of the testosterone oenanthate metabolites by Corynebacterium jeikeium and the possible metabolites identity.

\begin{tabular}{lcccccc}
\hline Substance & $\begin{array}{l}\text { Retention } \\
\text { time }\end{array}$ & $\begin{array}{c}\text { Mass } \\
\text { peak }\end{array}$ & $\begin{array}{c}\text { Molecular } \\
\text { Weight }\end{array}$ & $\begin{array}{c}\text { Possible } \\
\text { Molecular } \\
\text { formula }\end{array}$ & $\begin{array}{c}\text { Suggested possible } \\
\text { compound }\end{array}$ & $\%$ \\
\hline Substrate & 19.6 & 114 & 400 & $\mathrm{C}_{26} \mathrm{H}_{40} \mathrm{O}_{3}$ & Testosterone oenanthate & 100 \\
Metabolite I & 18.47 & 237 & 270 & $\mathrm{C}_{19} \mathrm{H}_{26} \mathrm{O}$ & Androstadienone & 22.3 \\
Metabolite II & 19.7 & 287 & 290 & $\mathrm{C}_{19} \mathrm{H}_{30} \mathrm{O}_{2}$ & 5- $\alpha$-dihydrotestosterone & 75.3 \\
\hline
\end{tabular}

\section{Assessment of inhibition of malodor production by gas chromatography mass spectrometry (GC/MS)}

The effect of malodor production inhibitors on conversion of substrates into metabolites by the action of $C$. jeikeiumwas quantitatively assessed after 72 hours using GC/MS (Table 5 and Figures 3, 4\&5). In the absence of inhibitor (Figure 2), 99.6\% oftestosterone ester substrate was converted into metabolites. In the presence of mastic gum (Figure 3), about $84.27 \%$ of the substrate was converted into metabolites. In the presence of ascorbic acid (Figure 4), only about $6.9 \%$ of the substrate was converted into metabolites. While in the presence of orlistat (Figure 5), about $0.6 \%$ of the substrate was converted into metabolites.

\section{Screening for malodor producing isolates from hydroxy progesterone caproate}

Ethyl acetate extracts of inoculated reaction mixture and controls were subjected to TLC. The mobile phase used was chloroform: ethanol $(9: 1 \mathrm{v} / \mathrm{v})$.It was found that only testosterone metabolizing isolates could metabolize hydroxy progesterone caproate and produce nonodorous metabolites.Lipophilic Corynebacteriaand Staphylococcus capitisisolates were found to be able to produce two major non-odorous metabolites (I \& II) from hydroxy progesterone caproate as the substrate with Rf values 0.9 and 0.5 in (chloroform :methanol). Metabolite I is more polar than the substrate with $\mathrm{Rf}$ value 0.43 and 
metabolite II which is less polar than the substrate with Rf value 0.58 (Table 2). Controls containing substrate showed the Table 5. Quantitative assessment of inhibitors of malodor formation using GC/MS.

\begin{tabular}{lccccc}
\hline $\begin{array}{l}\text { Inhibitor of } \\
\text { malodor }\end{array}$ & $\begin{array}{c}\text { Concentration } \\
\text { of inhibitors } \\
(\mathrm{mg} / \mathrm{ml})\end{array}$ & $\begin{array}{c}\text { \% of converted } \\
\text { substrate into } \\
\text { metabolites }\end{array}$ & $\begin{array}{c}\text { \% of } \\
\text { unconverted } \\
\text { substrate }\end{array}$ & $\begin{array}{c}\text { Retention time of } \\
\text { the substrate. }\end{array}$ & $\begin{array}{c}\text { Peak } \\
\text { number }\end{array}$ \\
\hline $\begin{array}{l}\text { In absence of } \\
\text { inhibitor }\end{array}$ & - & 99.6 & 0.44 & 21.2 & 3 \\
Orlistat & 1.5 & 0.6 & 99.41 & 21.4 & 5 \\
Ascorbic acid & 0.25 & 6.9 & 93.02 & 20.24 & 5 \\
Mastic gum & 0.25 & 84.27 & 15.73 & 20.6 & 11 \\
\hline
\end{tabular}

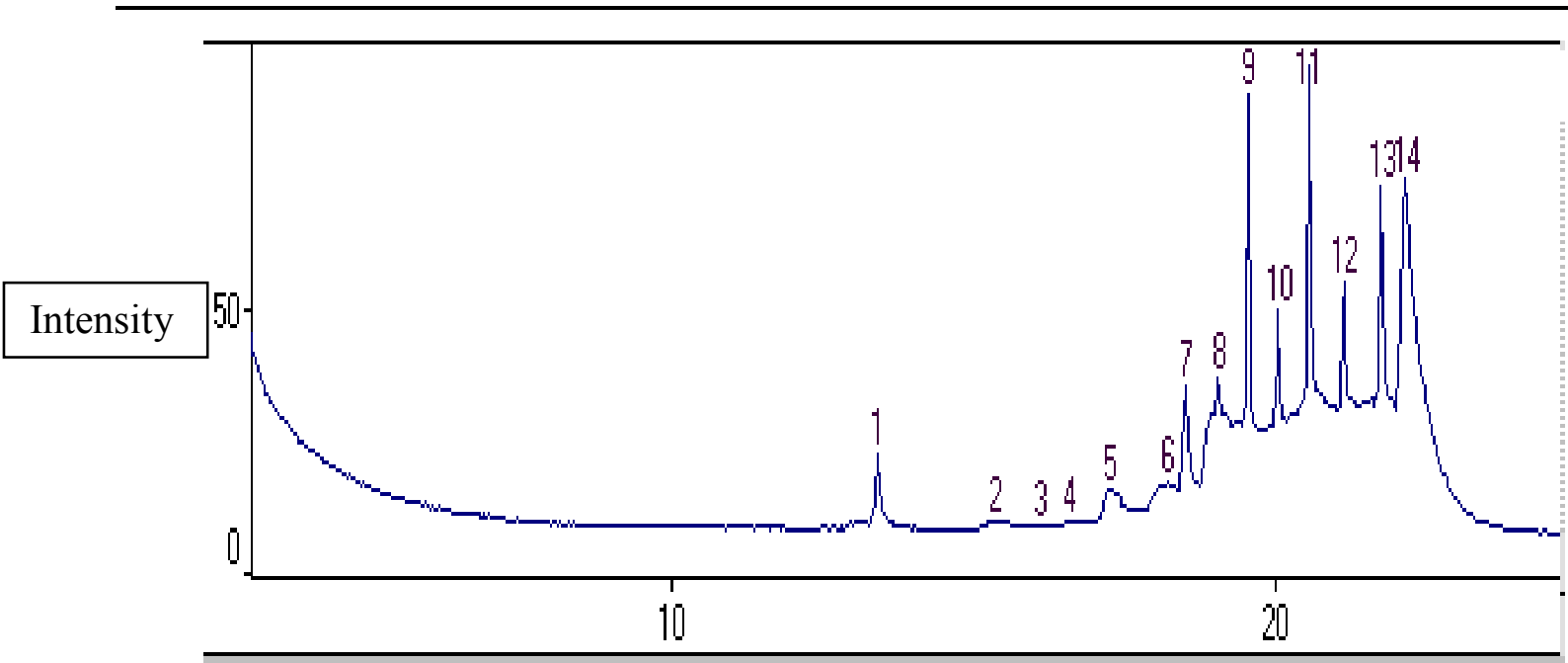

Figure 3. GC/MS analysis of the extract of $C$. jeikeium culture containing testosterone oenanthate as substrate in the presence of mastic gum after 72 hours incubation, showingabout $84.27 \%$ of the substrate was converted into non odorous metabolites.

Intensity

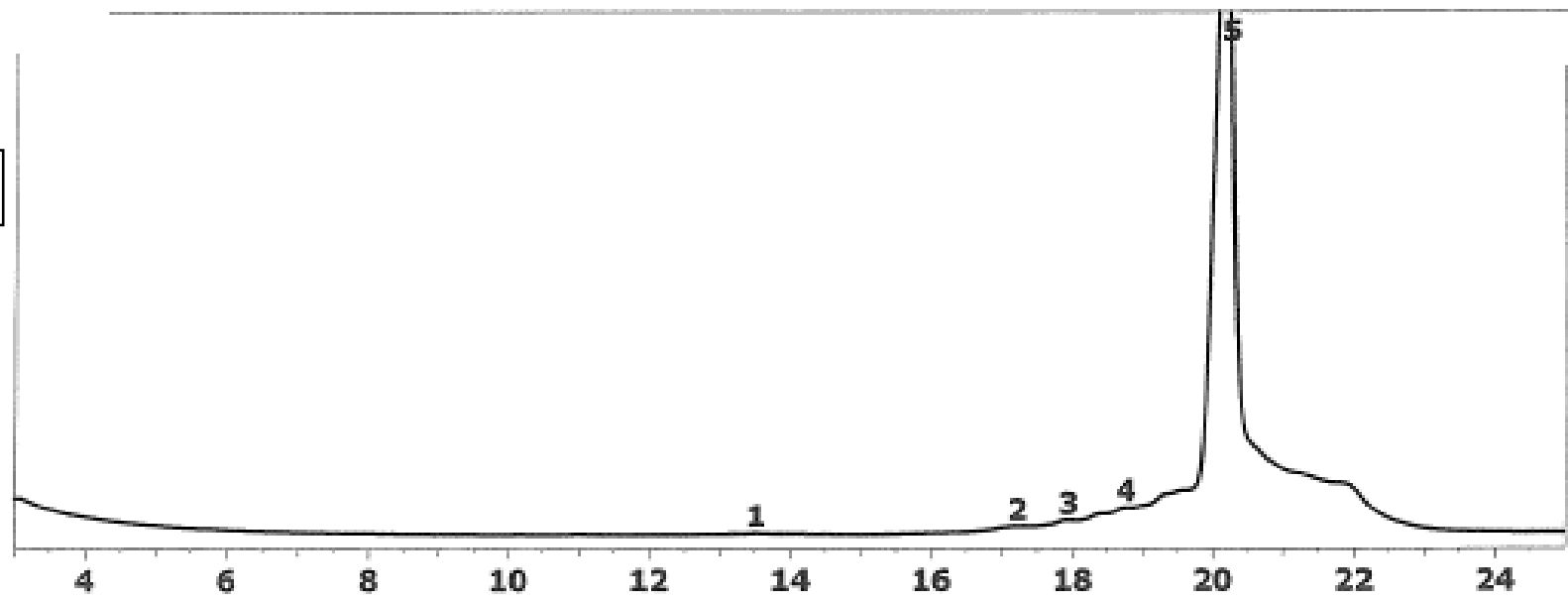

Figure 4. GC/MS analysis of the extract of $C$. jeikeium culture containing testosterone oenanthate as substrate in the presence of ascorbic acid after 72 hours incubation, showing only about $6.9 \%$ of the substrate was converted into metabolites. 


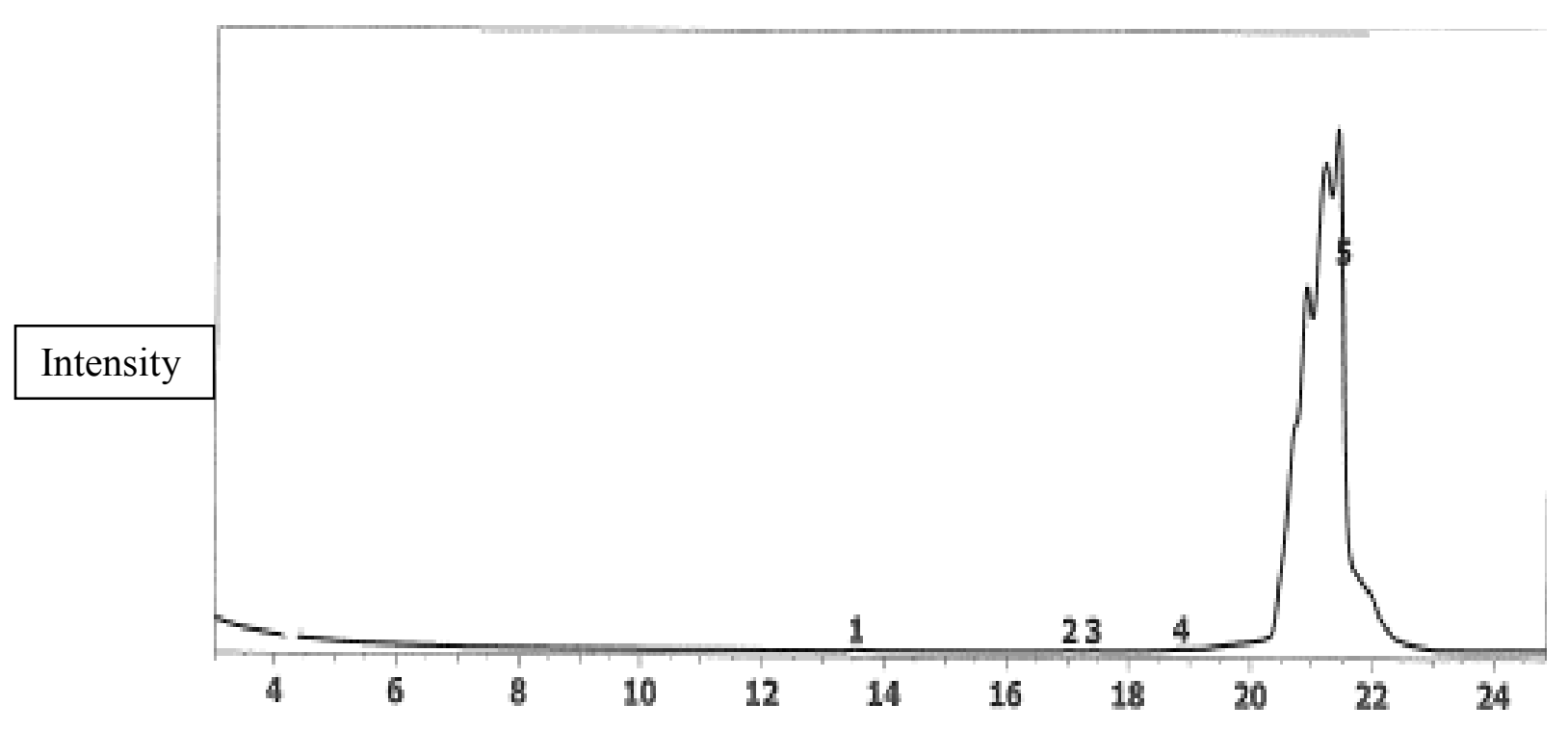

Figure 5. GC/MS analysis of the extract of $C$. jeikeiumculture containing testosterone oenanthate as substrate in the presence of orlistat after 72 hours incubation, showing only about $0.6 \%$ of the substrate was converted into metabolites. 


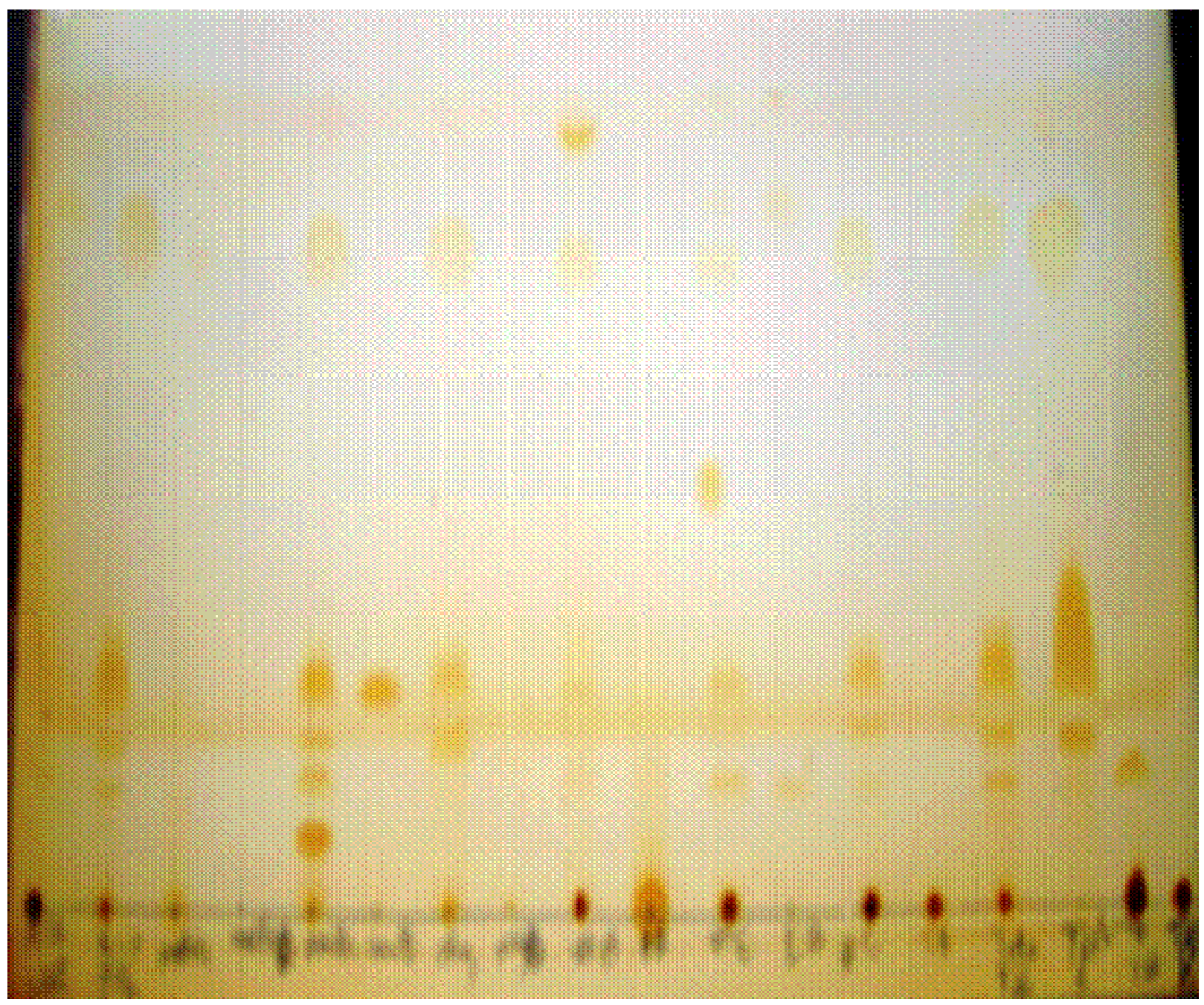

Figure6. Thin layer chromatography of culture extracts of $C$. jeikeium in the presence and absence of various inhibitorsafter $72 \mathrm{hrs}$ incubation. Lane 1: reaction mixture at zero time; Lane 2: reaction mixture after incubation; Lane 3 reaction mixture after incubation with mastic gum; Lane 4, mastic gum control; Lane 5, reaction mixture after incubation with vanillin; Lane 6, vanillin control; Lane 7, reaction mixtureafter incubation with orlystat; Lane 8, orlystatcontrol; Lane 9, reaction mixture after incubation with retinylpalmitate; lane 10, retinylpalmitatecontrol; Lane 11, reaction mixture after incubation with $\alpha$-tocopherol acetate; Lane 12, $\alpha$-tocopherol acetatecontrol ; Lane 13, reaction mixture after incubation with ascorbic acid; lane 14, ascorbic acid control; lane 15, reaction mixture after incubation without Tween 80; Lane 16, testosteroneoenanthatecontrol; Lane 17, reaction mixture after incubation without testosterone; Lane 18, Tween 80 blank.

\section{DISCUSSION}

The generation of malodor on various sites of the human body is caused by the microbial biotransformation of odorless natural secretions into volatile odorous molecules. On the skin surface, distinctive odors emanate, in particular, from the axilla, where a large and permanent population of microorganisms thrives on secretions from the eccrine, apocrine, apoeccrine and sebaceous glands (Leyden et al., 1981). Axillary odor is due to a large number of odorous substances, including aliphatic fatty acids, $3 \mathrm{M} 2 \mathrm{H}$ acids, odorous androst-16-ene steroids, as well as the 2-ene steroid (Gower et al., 1997).

The most fundamental approach to deodorancy is to prevent the formation of these odorous compounds, the bacteria present in the axilla are largely responsible 
for the biotransformations leading to odorous compounds, and consequently the earliest and most widespread strategy aimed at the inhibition of odor formation has involved the use of antimicrobials (Woodruff, 1994).

The control of malodor is achieved by various mechanisms:the use of antimicrobial agents, $\mathrm{pH}$ modification, enzyme inhibitors (esterase), and inhibition of odorous steroid formation, inhibition of volatile fatty acid formation, inhibition of protein and amino acid biotransformation, inhibition of bacterial adherence, odor counter-actants, and fragrances and modifiers of perception.

In the present study, bacterial isolates were recovered from armpit samples taken from individuals with distinctive production of malodor. The isolates obtained belonged to the most commonly isolated genera from axilla (Marples and Williamson, 1969; Kloos and Mussolwhite, 1975; Leyden et al., 1981; Jackman and Noble, 1983; Cox, 1987).The isolates were screened for their ability to produce malodorous metabolites from testosterone oenanthate ester. Malodor producing isolates were detected by sensory assessment and thin layer chromatography (TLC). Except for $S$. capitis isolates that produced urinous bad odor, there was no distinctive malodor produced by Staphylococcus isolates. This is the first time to report malodor production by Staphylococcus capitis from testosterone. All Micrococcus isolates produced a bad rancid odor, but not a sweaty urinous odor.

The tested isolates of lipophilic species of Corynebacterium (C. jiekieum and $C$. macginleyi) produced the most offensive sweaty urinous odor, concurrently with the metabolic transformation of testosterone oenanthate, as demonstrated by TLC, whereas other non lipophilic Corynebacterium species produced a less distinctive odor. Lipophilic Corynebacterium isolates were reported to produce malodorous metabolites from testosterone (Leyden et al., 1981; Jackman and Noble, 1983; Gower et al., 1985; Nixon et al., 1986 \& 1987; Froeb et al., 1990; and Rennie et al., 1990).

Using hydroxy progesterone caproate as a substrate instead of testosterone, all Micrococcus isolates showed no distinctive metabolites spots, but exhibited a bad rancid odor. In agreement with these findings, Decr'eauet al. (2003) found that Micrococcus spp. did not metabolize sterols. On the other hand, all tested Corynebacterium isolates showed distinctive metabolites spots but did not exhibit distinctive malodor. In accordance with this, no malodorous metabolites were obtained from pregnenolone which is another $\mathrm{C} 21$ putative female hormone (Austin and Ellis, 2003).

GC/MS was used for quantification of testosterone ester and identification of its metabolites by comparing the molecular ions formed and fragmentation patterns, retention time, molecular weight with previously reported data. Two major metabolites were found. Predictions were made from molecular ions formed and different fragmentation patterns. Metabolite I (22.3\% of total metabolites) would match androstadienone (Labows, 1988) which is known to have urinous odor (Gower et al., 1997b. Labows, 1988). The second metabolite II $(75.34 \%$ of total metabolites) could be 5- $\alpha$ dihydrotestosterone (Nixon et al., 1984) which is not known to exhibit odor. When compared with the previously reported data (Nixon et al., 1984), and supposed molecular formula would suggest that similarly (Table 1). Androstadienone could be formed by the dehydration at the 17hydroxy group and the formation of a double bound at C-16 (Gower et al., 1997b), whereas 5a-dihydrotestosteroneis formed by reduction of the double bond of testosterone (Nixon et al., 1984).

Rennie et al., (1990) have found that many aerobic coryneforms could 
transform testosterone, the principal metabolites being $5 \alpha-$ and 5 - $\beta$-dihydrotestosterone, androstenedione, and 5$\alpha$ - and 5 - $\beta$-androstanedione.

In the present study, some components of deodorant products and raw natural products material or chemical with potential deodorant activities were tested for their ability to prevent malodorous metabolites formation from testosterone oenanthate. Materials with known antimicrobial activities were used at subinhibitory concentrations to exclude their effect as inhibitors of microbial proliferation as a mechanism of deodorant activities.

Cupric sulfate, zinc sulfate, triethyl citrate, orlistatselenium dioxide, ascorbic acid and EDTA were found to inhibit malodor production from testosterone ester without the appearance of extra spots by TLC. In agreement with these finding, Froebet al., (1990) reported thatcupric sulfate, zinc sulfate, di-sodium EDTA inhibit malodor forming metabolic pathway. $\alpha$-tocopherol acetate, and retinyl palmitate reduced the odor intensity but produced one extra spot with TLC, these were found to be attributed to interaction with the filtrate of the test culture. The fact that the steroidal metabolism in bacteria is accelerated by a number of oxidoreductase enzymes as 5- $\alpha$-reductase, 3hydroxy steroid dehydrogenase, 1-ene reductase, 4-ene reductase and other enzymes, could explain the present and the previously reported findings (Decr'eau et al., 2003; Gower et al., 1988; Nixon et al., 1986) that some antioxidants were able to inhibit the possible malodorous metabolites.

Vanillin, Mastic gum, bergamot oil, peppermint oil, alum, ethyleneglycol, polyethylene glycol, triclosan, alum and musk xylol could not inhibit the metabolism of testosterone ester. The fragrant components, namely vanillin, peppermint oil and bergamot oils, seem to have worked through masking the bad odor. Mastic gum seemed to have sequestered the metabolite preventing its extraction, as appeared in TLC, or it could have led to the production of other metabolites of less intensive odor as appeared in its GC/MS charts. The other components could not inhibit the urinous sweaty odor at the tested concentrations, such compounds possibly owes its deodorant action through their antimicrobial activities as the case with glycols and triclosan (Fearnley and Cox, 1983; Cox, 1987; Block, 1991) or through their antiperspirant activities as with alum (Quatralet al., 1997; Piérardet al., 1993 ).

Triethyl citrate was proposed to act as deodorant through preferential hydrolysis (competitive inhibition), by esterases produced by sweat metabolizing bacteria (Osberghaus, 1980).

The present findings demonstrate that vanillin, peppermint and bergamot oils masked the formed odor but did not inhibit metabolite formation.

Orlistat (tetrahydrolipstatin) is a semisynthetic derivative of naturally occurring lipase inhibitor (lipase is specific estrase) was found to inhibit malodor formation from testosterone onenthateby Corynebacteria. Here it was shown for the first time, that orlistat was able to inhibit malodor production. A number of non-antibacterial esterase inhibitors have been patented for use in deodorants (Maurer et al., 1995; Wachter et al., 1995).

GC/MS analysis revealed almost complete $(99.6 \%)$ conversion of testosterone ester into metabolites in $C$. jeikeium culture after 72 hour incubation. In the presence of mastic gum, about $84.3 \%$ of the substrate was converted into metabolites, yet no malodor was found, indicating that mastics inhibited the malodor associated metabolism possible by directly interacting with and sequestering the substrate or metabolites (as TLC show only scanty faint spots of the substrate) or through diverting the metabolic reaction to different pathways leading to the formation of odorless metabolites or the formation of 
malodorous metabolites in very low quantity. While ascorbic acid dramatically inhibited testosterone metabolism (6.9\% of the substrate was converted into metabolites), orlistat almost completely prevented its metabolism (only $0.6 \%$ of the substrate was converted into metabolites).

The present findings demonstrate the high potentials of orlistat, ascorbic acid and mastic gum as deodorants. Further work is required to define their mode of action and test their applications as deodorant ingredients.

\section{REFERENCES}

1. American Society for Testing Material International Standards (ASTM) Committee E-18(1988): Standard practice for the sensory evaluation of axillary deodorancy.1988. ASTM Standards, vol 15.07, designation: E1207-87:51-66.

2. Austin, C; Ellis, J (2003): Microbial pathways leading to steroidal malodour in the axilla. Journal of steroid biochemistry and molecular biology.87:105-110.

3. Bhargava, H.N.; Leonard, P.A. (1996): Triclosan: applications and safety. Am J Infection Control 24:209-218.

4. Block, S.S.; Bruch, M.K. (1983): Methods of Testing Antimicrobials Used Topically in Humans. In, Disinfection, Sterilization, and Preservation. P 946-964. $4^{\text {th }}$ Ed. By, Lea and Febiger, Philadelphia.

5. Block, S.S. (1991): Definitions of terms, p. 18-125. In Block S.S. (ed.), Disinfection, sterilization, and preservation, 4th ed. Lea \&Febiger, Philadelphia, Pa.

6. Cox, A.R. (1987): Efficacy of the antimicrobial agent triclosan in topical deodorant product recent developments in vivo. J. SocCosmetChem .38:223231.

7. Decréau, R. A.;Marson,C. M.; Smith, K. E.; Behan, J. M. (2003): Production of malodorous steroids from androsta5,16-dienesand androsta-4,16-dienes by Corynebacteriaand other human axillary bacteria. Journal of Steroid Biochemistry \& Molecular Biology, 87: 327-336.

8. Edwards, A.; Jones, S.M.; Davies N.W. (2003): Sex and season influence gonadal steroid biosynthetic pathways, end product production and steroid conjugation in blotched blue tongued lizards (Tiliquanigrolutea).General and Comparative Endocrinology 134:131138.

9. Fearnley, C. ; Cox, A. R. (1983): A new microbiological approach to the assessmenotf underarm deodorants, Int. J. Cosmet. ci., 5: 97-109.

10. Froebe, C.; Simone, A.;Charig, A.; Eigen,B.( 1990): Axillary malodor production-a new mechanism. J. Soc. Cosmet. Chem. 41:173-185.

11. Gower, D. B.; Mallet, A.; Watkins, W.; Wallace, L. (1997a): Transformation of steroid sulfates by human axillary bacteria. A mechanism for human odor formation? Biochem. Soc. Trans. $25,16 \mathrm{~S}$; Use of GC-MS in studies of androst-16-ene and androgen biosyntheses in human testis. J. Steroid Biochem. Mol Biol. 60: 137-146.

12. Gower, D. B.; Mallet, A.; Watkins, W.; Wallace, L. ;Calame, J. (1997b): Capillary gas chromatography with chemical ionization negative ion mass spectrometry in the identification of odorous steroids formed in metabolic studies of the sulphates of androsterone, DHA and $5 \alpha$-androst-16en-3 $\beta$-ols with human axillary bacterial isolates. J. Steroid Biochem. Mol. Biol. 63: 81-89.

13. Gower, D.B.; Bird, S.; Sharma, P; House, F. (1985): Axillary androstenone in men and women relationship with olfactory acuity to odorous 16-androstenes Experentia 41: 1134-36.

14. Gower, D.B.; Nixon, A.; Mallet, A.I. (1988): The significance of odorous steroids in axillaryodour. In: $\mathrm{S}$ van Toiler, GH Dodd, eds. Perfumery: The 
Psychology and Biology of Fragrance. Cambridge, U.K.: Chapman and Hall, pp 47-76.

15. Haustein,U.F.;Herrmann,J.;Hoppe,U.; Engel,W.;Sauermann, G.(1993): Growth inhibition of coryneform bacteria by a mixture of three natural products

HGQ.J.Soc.Cosmet.Chem,44:211-220.

16. Jackman, R.; Noble, W. (1983):Normal axillary skin microfiora in various populations.Clin. Exp. Dermatol. 8:259-268.

17. Kloos, W.;Mussolwhite, M. (1975): Distribution and persistence of Staphylococcus and Micrococcus species and other aerobic bacteria in human skin. Appl Microbiol.30:301

18. Koneman, E.W.; Allen, S.D.;Janda, W.M.;Schreckenberger, P.C.; Winn, W.C.(1997a): Guidelines for the collection, transport, processing, analysis and reporting of cultures from specific specimen types .In Color Atlas And Textbook of Diagnostic Microbiology.P.121-162. 5th Ed. By J.B. Lippincott company, Philadelphia.

19. Labows, J. (1988): Odor detection, generation and etiology in the axilla. In Antiperspirants and Deodorants, eds C. Felger, and K. Laden, Marcell Dekker, New York, pp321-343.

20. Leyden, J.;McGinley,K.;Holzle, E.;Labows, J.; Kligman, A. (1981):The Microbiology of the Human Axilla and its Relationship to Axillary Odor. J. Inv. Derm., 77: 413-416.

21. Leyden, J.; McGinley, K.; Nordstrom, K.; Webster, G. (1987):Skin microflora. J Invest Dermatol; 88: $65 \mathrm{~s}-72 \mathrm{~s}$.

22. Marples, R.; Williamson, P. (1969): Efects of dimethylch1 orotetracycline on human cutaneous micoflora. ApplMicrobiol 18:228.

23. Maurer, K.;Tesmano, H.;Wachter, R.(1995): Use of fat-soluble partial ester(s) of hydroxy-carboxylic acids as active deodorant in topical composition for suppressing body odour and inhibiting activity of esterase(s) decomposing sweat.Patent DE 4343264

24. NCCLS (National Committee for Clinical Laboratory Standards) (2002): Methods for dilution antimicrobial susceptibility tests of bacteria that grow aerobically. ApprovedStandard M100-S12. Wayne. PA,USA; NCCLS.

25. Nixon, A.;Jackman, P.J.H.; Mallet, A.I.; Gower, D.B. (1987): Testosterone metabolism by pure and mixed cultures of human corynebacteria, FEMS Microbiol. Lett. 41: 53-58.

26. Nixon, A.; Mallet, A.I.; Gower, D.B. (1988): Simultaneous quantification of five odorous steroids in the axillary hair of men. J. Steroid Biochem., 29: 505-510.

27. Nixon, A.; Mallet, A.I.;Jackman, P.J.H.; Gower, D.B. (1984):Production of 5 - $\alpha$ - and 5 - $\beta$-testosterone by isolated human axillary bacteria, FEMS Microbiol. Lett. 25:153-157.

28. Nixon, A.; Mallet, A.I.;Jackman, P.J.H.; Gower, D.B. (1986): Testosterone metabolism by isolated human axillary Corynebacterium spp.: a gas-chromatographic massspectrometric study, J. Steroid Biochem. 24: 887-892.

29. Osberghaus, R. (1980): Nonmicrobiocidal deodorizing agents. Cosmet Toiletries 95:48-50.

30. Piérard, G.E.;Elsner, P.; Marks, R.; Masson, P.;Paye, M. (2003): EEMCO Guidance for the Efficacy Assessment of Antiperspirants and Deodorants,Skin Pharmacol Appl. Skin Physiol 16:324-342.

31. Quatrale, R.P.; Coble, D.W.; Stoner, K.L.;Felger, C.B.(1997): The mechanism of antiperspirant action of aluminium salts. II. Histological observations of human eccrine sweat glands inhibited by aluminiumchlorhydrate. J. Soc. Cosmet. Chem. 32:195-222. 
32. Rennie, P.; Gower, D.B.; Holland, K.; Mallet, A.; Watkins, W. (1990): The skin microflora and the formation of human axillary odor. Int. J. Cosmet. Sci., 12: 197-207.

33. Rennie, P.J.; Holland, K.T.; Mallet, A.I.; Watkins, W.J.; Gower, D.B. (1988): Interconversion of androst-16ene steroids by human axillary aerobic coryneform bacteria. Biochem. Soc. Trans. 17:10271028.

34. Starkenmann, C;Mayenzet, F;Brauchli, R;Troccaz, M.(2013):5 $\alpha$-Androst-16-en-3 $\alpha$ ol $\beta$-D-glucuronide, precursor of $5 \alpha$-androst-16-en- $3 \alpha$-ol in human sweat..Chem Biodivers. 10(12):2197-208.
35. Wachter, R.; Maurer, K.;Tesmano, H. (1995): Use of monoalkyl or dialkyl ester(s) of aliphatic, satd. di-carboxylic acids as active deodorant in topical composition for suppressing body odour by inhibiting activity of esterase(s) decomposing sweat. Patent DE 4343265.

36. Zeng, X.; Leyden, J.;Lawley, H.;Sawano, K.; Nohara, I.; Preti, G. (1991): Analysis of the characteristic odors from the male axillae. J. Chem. Ecol., 17: 1469-1492.

37. Zeng, X.; Leyden, J.J.; Brand, J.;Spielman, A.I.; McGinley, K. ;Preti, G. (1992): An investigation of human apocrine gland secretion for axillary odor precursors. J. Chem. Ecol. 18: 1039-1055.

\footnotetext{
تقييم خارج الجسم لفعالية بعض مكونات المستحضرات المزيلة لرائحة العرق وتقييم قرة كل من الاورليستات وحمض الاسكوربيك و صمغ المستكه على تثبيط المسار الأيضي المكون للرائحة الكريهة

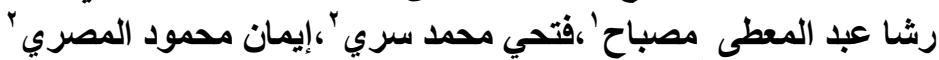

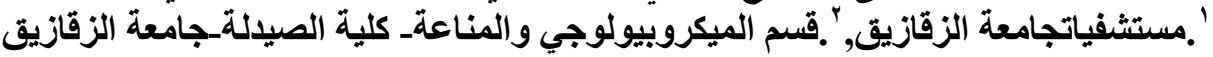

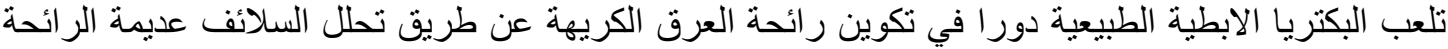

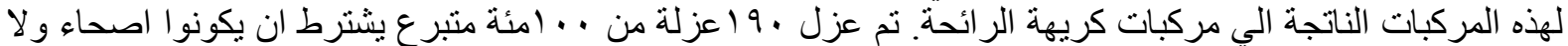

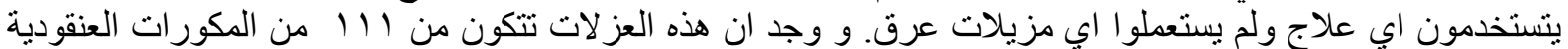

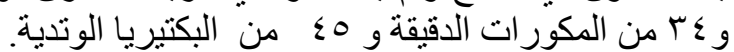

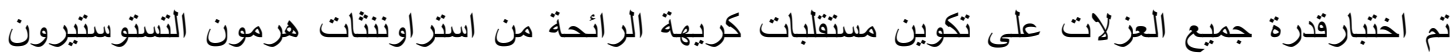

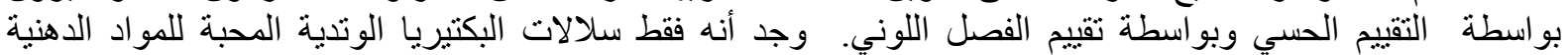

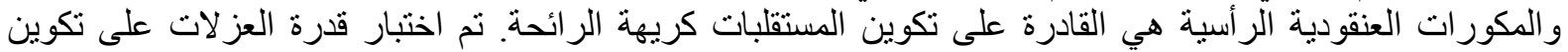

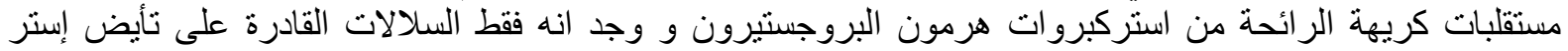
هرمون تستوستيرون هي القادرة على تأيض إستر بروجستيرون هيدروكسي ونتج عن هذا التفاعل الأيضي مستقلبات عديمة الر ائحة. تم تحليل المستقلبات كريهة الر ائحة للتستوستيرون و التعرف عليها باستخدام الفصل الغازي تحليل الطيف الكمي.

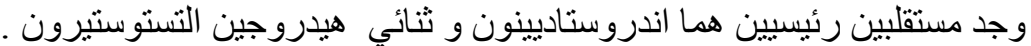

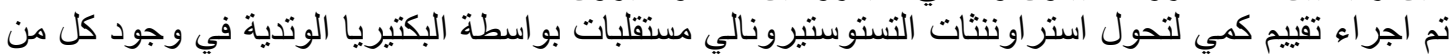

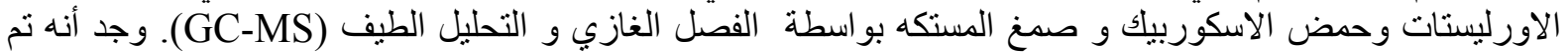

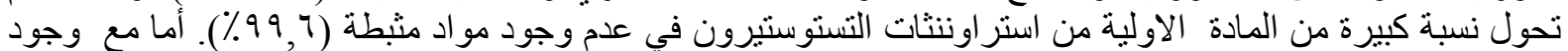

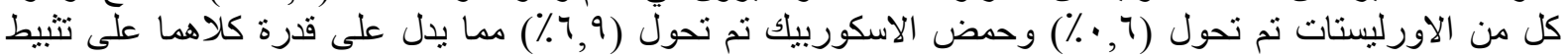

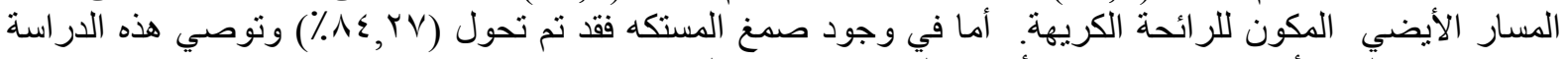
باستخدام هذه المو اد أو اضافتها كمكونات أساسية لمزيلات رائحة العرق العرة العرة
} 